\title{
Business Models and Internet of Things
}

\author{
Dragos TOHANEAN \\ University of Economic Studies, Bucharest, Romania \\ tohanean_dragos@yahoo.com
}

PICBE |

1192

\author{
Anca VASILESCU \\ Transilvania University of Brasov, Romania \\ vasilex@unitbv.ro
}

\begin{abstract}
Information technology has massively transformed the world of business over the past fifty years - first individual functional areas within companies ("first wave"), later increasingly also crossdivisional value-added processes and trade ("second wave"). Those companies that recognized the tremendous economic potential of these upheavals and consistently adapted, profited enormously many others, however, fell dramatically. At the same time, innovative startups emerged that successfully created and occupied new markets. With the Internet of Things (IoT), the third digital wave is currently rolling up. Their impact will be enormous - both for our everyday lives and for many industries that have so far been largely spared the disruptive power of digital transformation. Accordingly, the challenges facing most companies today are: understanding more complex competition, acquiring new digital technologies, making existing offerings smart, developing new services, networking production, efficiently analyzing vast amounts of data, and building viable organizations to push all this forward. The IoT is a driver for digitization. By analyzing machine data, the use of sensors and the intelligent realtime processing of huge amounts of data in the cloud, new business models are created. With the information gained, companies are able to improve their value chain. However, one of the most difficult issues in this context for many companies is how they can further develop their existing business model or establish successful new business models that will be based on new technologies and IoT. To investigate resulting impacts, we draw on the existing business models and deduct specifics for the Internet of Things. Building on this, in order to reach the aims of the paper the authors will use a descriptive research method and a case study in order to present how new business models work with the IoT.
\end{abstract}

Keywords: Internet of Things, Business Models, DriveNow

\section{Introduction}

The Internet of Things, IoT for short, describes the networking of physical things with the Internet. For many of these things, until a few years ago it was hard to imagine that one day they would be part of a huge network. It is estimated that by 2020, between 20 and 100 billion things will be networked worldwide.

The number makes it clear what a huge potential the entire IoT industry is credited with. It will be exciting to see how companies with innovative products - made possible by completely new business models - achieve their share in the market.

New technical achievements often enable new business models. IoT can be roughly divided into two business model groups: "Digitally charged products" and "Sensor as a service" (Bucherer \& Uckelmann, 2011). 
Digitally charged products describe the idea of connecting a physical object to the Internet and thereby generating added value in the form of a digital service. This makes it possible to extend the previous, locally experienced benefits of a thing to a new, digital.

Another IoT business model is "Sensor as a Service" (Bucherer \& Uckelmann, 2011). In this case, a particular product is not expanded by a digital service, but a new service is generated based on sensor data. A benefit is generated exclusively with the collected data of the sensors.

IoT fuels new business models and opens up new opportunities for industrial companies in particular to cut costs and differentiate themselves from their competitors. It is often neglected in corporate practice that it is not just about technology, but also about using the value-adding potential of the IoT strategically in order to solve problems that are relevant to customers.

A business model is the (simplified or structuring) mapping of selected aspects of the company's resource transformation (Gassmann, Frankenberger, et al., 2018) as well as its exchange relationships with other market participants. IoT changes the way of how current business model work, bringing them to a new era.

\section{Literature Review}

We are in the age of business model innovation. Digitization, Industry 4.0 and the Internet of Things call for a constant realignment of the business. Before the existing business model can be collected, analyzed and further developed, an understanding of the terms used is required. To date, the origin of the term "business model" has not been clarified in either science or practice. Different disciplines claim the introduction of the concept, assigning the origins to different sources.

In classic strategy literature, the concept of the business model does not exist (Wikipedia, 2019). In 2010, economist David Teece, in his publication Business Models, Business Strategy and Innovation stated that there is no theoretical foundation for the concept of the business model. (Teece, 2010). In the 1950s, US management expert Peter Ferdinand Drucker coined the term "logic of business" (Drucker, 1994), creating a predecessor definition of what is now understood in business and management theory as the "business model". A business model describes the basic logic of how an organization creates value. In doing so, the business model determines ... what an organization offers - that is of value to customers, how values are created in an organization, how the created values are communicated and transmitted to the customer, how the created values are "captured" in the form of revenues by the company, how the values are distributed in the organization / stakeholders and how the basic logic of value creation is developed to ensure the sustainability of the business model in the future (Bieger, 2011).

With the emerging knowledge industry, the growing importance of the Internet and the associated expansion of eCommerce, business models have become increasingly popular, especially in IT circles. Increased outsourcing and offshoring of tasks, activities and entire processes in conjunction with a burgeoning start-up culture also brought the concept of a business model more and more to the foreground. In this new concept a business model describes the basic principles according to which an organization creates, communicates and records values (Osterwalder, 2014). 
Besides the emerging trend of business model innovation we also have an increase in the digital world. With digital evolution, not only the number of Internet-enabled devices is increasing, but also the ability to connect people, processes, data and things wirelessly. In the context of Industry 4.0, systems and devices already exchange measured values and sensor data. The basis for this is wireless networking, which is characterized by secure network connections and a flexible and robust infrastructure (Fraunhofer IIS, 2019). It is also called the era of Internet of Things (IoT). IoT refers to the networking of objects with the Internet, so that these objects communicate independently via the Internet and so can do various tasks for the owner. The scope of application extends from general information supply via automatic orders to warning and emergency functions. On its turn, the IoT heralds a whole new era of competition. With its dynamics, IoT is changing entire industries, redefining old industries and creating new ones. This will affect the core business of each company. As the concept IoT creates an integrated relationship between business and technology, representing a key element of today's business models.

\section{Methodology}

The authors employed a quantitative research method and a case study. The quantitative method in empirical social research includes all procedures for the numerical representation of empirical facts, but also to support the conclusions of the empirical findings with means of inferential statistics. Quantitative methods include sample selection, data collection and analysis. The case study presents a complex analysis of a contemporary phenomenon. Also, as a research method it includes five main components: a study's question, its propositions (if any), its unit of analysis, the logic linking the data to the propositions and the criteria for interpreting the findings (Yin, 1994) as cited in Tellis (1997).

In order to gather the needed information the authors used various sources such as journals (e.g., Journal of the Knowledge Economy, Strategic Management Journal, Review of Financial Studies, European Accounting Review), reports and books from the fields of management, IT and innovation, or corporate reports of IoT - through a desk research and a case study on the German company DriveNow (DriveNow, 2018). These sources were found both in electronic databases (e.g., Springer, Google Scholar, Amazon) and libraries (e.g., Central University Library "Carol I”, British Council Romania).

\section{IoT at a glance}

The Internet of Things area of research and its applications, especially focusing on sensing the environment in an intelligent manner, provide state-of-the art solutions for incremental business transformation as well as radical business changes. This section presents some important aspects of economic systems together with the key characteristics and approaches for IoT. The Internet of Things involves remotely controlled or autonomous mechanical devices with embedded intelligence which can sense their environment, their state and can even act accordingly. Merging the IoT physical properties with smart devices provides opportunities for emerging applications with inherently autonomic properties and selfevaluation functions. Such applications that adopt the IoT paradigm do not only offer opportunities for new innovative business models, but they will also improve the quality of citizens' life and will provide more effective and efficient support to humans. 
The Internet of Things or the IoT concept has been present since Nikola Tesla envisioned a wireless world in 1904 (Tesla, 1904), but the term was coined by Kevin Ashton who declared in 2009 in (Ashton, 2009) that the phrase Internet of Things first appeared as the title of one of his presentations made in 1999. But the first smart appliance was a Coke machine at Carnegie Mellon University in the early '80s, where students managed to connect the machine over the internet by writing some software that allowed to "check the status of the machine and determine whether or not there would be a cold drink awaiting them; and consequently the students could decide to make the trip down to the machine" (CokeMachine, 2019).

Two ideas are relevant for an initial definition of the Internet of Things. In 1999, Neil Gross stated that "in the next century, planet earth will don an electronic skin. It will use the Internet as a scaffold to support and transmit its sensations" (Gross, 1999). Today, the TechnoPedia portal states that "first version of the Internet was about data created by people, while the next version will be about data created by things" (TechoPedia, 2019). The interest of connecting every physical object or thing on the internet under the modern approach of the IoT is undeniable, but it requires specific "architectures that enable scalable, autonomous and robust solutions" (Eleftherakis et al., 2015) ready to support adaptive systems' behavior.

The IoT elements come together in three global components, as follows (Gubbi et al., 2013): (a) hardware - naming sensors, actuators and other specific hardware components ready to involve the system in communications, (b) middleware - naming ready to use memory components and tools for data computing and analytics and (c) presentation - the support for connecting the entire embedded system with its users by specific platforms and applications.

The authors offer in (Koreshoff et al., 2013) a valuable selection of specific IoT hardware devices, as follows: the IoT devices include sensors - for measuring the environmental context, actuators - ready to act back into their environment through physical operations, and nodes - to keep the system alive by managing the information, the coordinators and the applications. Therefore, IoT becomes the place where all these hardware devices merge seamlessly with the environment around us. The interest of this paper is to give a modern solution for connecting such everyday existing objects in favor of embedding intelligence into our environment and business.

As an example, in (Eleftherakis et al., 2015) an interesting and valuable middleware for a specific bio-inspired distributed architecture of the Internet of Things is proposed and it is proved that the system is capable to offer autonomous operation to its interconnected and interacting cyber or physical entities. The interconnections and the interactions among the IoT entities, whether those entities are humans or machines, are the main target which the IoT paradigm is focused on. It follows that an overlay network of uniquely identifiable entities together with an event-driven and service-oriented interaction are essential for the concept (Eleftherakis et al., 2015) and they represent a hierarchical architecture based on systems and sub-systems which can control other internet connected components in an intelligent manner.

Considering presentation as the third IoT component, the business models come exactly as appropriate and useful interpretation tools which can be designed for different innovative applications and can easily be supported by case-studies. The next sections will focus on specific examples ready to support these considerations. 
Even if there is no generally accepted definition for the Internet of Things, some recent contributions could be mentioned here. According to (Moon \& Pan, 2014), there are three perspectives which could the definition of IoT being based on, as follows: the support of the internet, the semantic context and the objects' perspective. Firstly, the internet-based IoT definition targets the network properties for connecting anything, from anywhere, by anyone. Secondly, the semantic-based definition is approaching IoT from the point of view of the context generated by the involved things and people in terms of data, information and commands together. Finally, the object-based definition regards the IoT as objects having an individual identifier and consequently benefitting from the object recognition and global location tracking information. An IoT-based distributed system becomes an ideal infrastructure to store and manage such information. These three perspectives could introduce major differences into an IoT system approach. For example, although the internal things are physically interconnected into an IoT system, "the diversity, heterogeneity and spatio-temporal dependency of specific data and resources" (Barnaghi et al., 2012) make things appear as disconnected at semantic levels. Payam Barnaghi et al. claim in the same (Barnaghi et al., 2012) that "IoT and using semantics in IoT are still in their early days" and consequently, new research directions like semantic web or semantic sensor web will swap the results with the IoT in the near future, with respect to the knowledge hierarchy updated in the context of IoT as follows: data - for raw sensory data, information - for structured data with semantics, knowledge - for abstraction and perception, and wisdom - for actionable intelligence.

Following all the previous considerations, the human's intervention should be minimal and people could experience the benefits of having smart devices. To achieve this, the Internet of Things needs to sustain its things capabilities and therefore to support a key system-level features very well highlighted in (Miorandi et al., 2012): "devices heterogeneity, scalability, ubiquitous data exchange through proximity wireless technologies, energyoptimized solutions, localization and tracking capabilities, self-organization capabilities, semantic interoperability and data management, embedded security and privacy-preserving mechanisms".

Each of these features introduces both challenges and opportunities for immersing the IoT into different areas, especially, human-computer interaction, business or economics. The higher IoT impact on these research domains is, the more there are needs to classify the research challenges to endorse the Internet of Things "from a concept into a well-engineered, commercially and technologically viable paradigm". The authors discussed this in (Miorandi et al., 2012) along with a taxonomy of three relevant IoT research areas: (1) computing, communication and identification technologies - which includes computing and business, (2) distributed systems technology - which includes enterprise computing with business process management, and (3) distributed intelligence - which includes business intelligence. According to the same (Miorandi et al., 2012), the main six application fields and market sectors ready to agree and to adopt the IoT technologies in the near future are: (1) environmental monitoring, (2) smart cities, (3) smart business, inventory and product management, (4) smart homes, smart buildings and intelligent building management, (5) health care and (6) security and surveillance. Out of these, the first and the third are primary for our interest here. Based on the scale of the impact of the data generated, four areas of the interconnection of objects are pointed out in (Gubbi et al., 2013) (1) home area for utilities, 
appliances, health, security or entertainment, (2) transport area, (3) community area including business intelligence and (4) national area support.

An interesting and comprehensive technology roadmap for the Internet of Things is presented in figure 1 (Office of the National Director, 2008) meant to highlight "the timing, features, and applications of significant technology milestones that would be necessary for developers of this technology to achieve (...) successful (equivalent to commercial) application - and possible disruption - is to occur by $2025 "$

PICBE | 1197

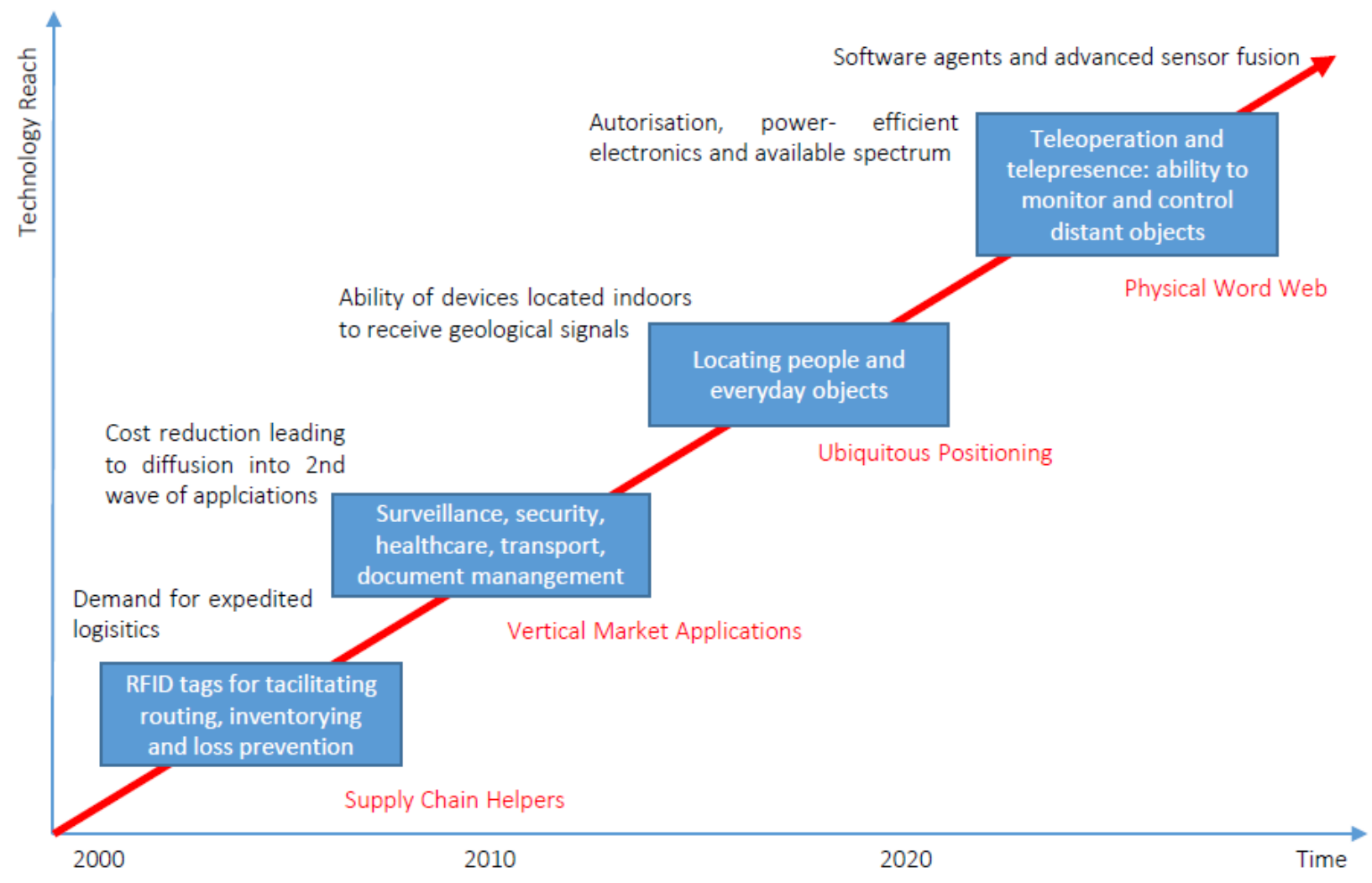

Figure 1. Technology roadmap for the Internet of Things

Source: SRI Consulting Business Intelligence

\section{How IoT shapes the business of the future}

More and more companies rely on the Internet of Things. However, its implementation is an enormous challenge for many of them. One of the most difficult questions in this context is: how can the existing business model be further developed and how can successful new business models be established? (Gassmann, Frankenberger, et al., 2018).

The IoT opens up many growth opportunities, especially in the area of supply and market positioning: many companies are already upgrading their products with free digital additional services and developing new monetizable services or products for existing target groups in order to exploit new sources of revenue. The coffee machine manufacturer Braun provides a classic example of the supply development: additional revenues are generated by networking existing and new coffee machines with cloud based services - this is done via a remote monitoring or remote maintenance service. Although the focus of activities is 
currently strongly on the offer of free digital additional services and the development of new services for existing target groups, market development and diversification trends are expected to be much stronger in the future, development of new target groups through IoT innovations or the addressing so far untapped markets with new services and products. The search engine giant Google is already doing it with the introduction of the TV stick Chromecast. This product allows the user to transfer content via Wi-Fi from the laptop to the TV. Not only does Google create an offer for existing Google service users, but for virtually anyone with a TV and laptop. The IoT will also have an enormous impact on almost all company activities in the medium term, below some examples:

Inbound and outbound logistics (Osterwalder \& Pigneur 2011): through the crosslinking of the entire supply chain, including goods and transport vehicles, logistics can be coordinated, monitored and optimized more easily and cost-effectively than before. The spectrum of applications ranges from virtual dashboards to data based optimization of route planning with real-time information at any location through to (partially) autonomously driving vehicles and delivery drones.

Production (Osterwalder \& Pigneur 2011): the interest in relatively simple IoT application scenarios, such as condition monitoring or predictive maintenance, is meanwhile high across industries. Ultimately, IoT leads to self-organized production, that is, the cyberphysical production system makes its own decisions and does its tasks largely autonomously. The share of production in total value added will tend to decline in most industry sectors in favor of software-based services around the core product.

Marketing and Sales (Osterwalder \& Pigneur 2011): thanks to the 'data flow' of networked products, customer segments can be identified much faster and customers can be approached based on specific data. Additional sales, cross selling and opportunities for new business are supported and customer loyalty strengthened. Also, intelligent IoT approaches can completely transform purchase decision processes.

Service: The most profound change comes with the IoT for the services area. While the possibilities of differentiation for manufacturers of physical products are steadily waning and their margins are falling, IoT technologies open up many new differentiation possibilities through software-based services (Porter, 2014). Examples include data-driven maintenance and servicing services, online dashboards to optimize machine efficiency, apps to control the smart home, and platforms to cross-link the manufacturer's devices with third-party devices. In special cases, even the product itself can be offered as a service: It is then no longer sold, but the billing is based on the useful life or similar parameters (Product-as-a-Service) (Bucherer \& Uckelmann, 2011).

From product to service - this results in 'hybrid products' in which the physical product and the corresponding services are inextricably linked. The relative value added is shifting away from production to service. Some leading producers are already earning 50 percent of their profits with downstream services. SAP (SAP, 2015) provides a good example of a data-driven shift in added value: in the meantime, the company no longer sells only his products as such, but also networks them with cloud and mobile services. It allows users to use the SAP system (SAP, 2015) at any place on any device. Basic functions are free of charge, while premium functions can be booked in the service platform or implemented on customer demand by SAP consultants (SAP, 2015). 
Companies offer software - This development also implies that almost every major corporation - irrespective of the sector - will have to become a software company in the medium term in order to compete in the future. One of the pioneers in this area is IBM. Rather than just supplying the 'hardware' as before, the business machine vendor has created its own platform, IBM Watson, which itself is a highly innovative IoT business model and provides customers with opportunities for their innovations, by analyzing data in real time and offering solutions on the spot.

The IoT is a key driver of business model innovation (Tohanean \& Toma, 2018). Established market participants and new digital competitors will seek to gain market share in all markets through business model innovation as well as creating and filling attractive new market segments. It is very important that companies make an inventory in good time, whether their existing business model is still future-proof against the background of the IoT and what potential can be tapped through targeted adjustments. The challenges are enormous, but the opportunities are as well (Cvijikj \& Michahelles, 2011).

\section{DriveNow a new way of doing business at BMW}

Car sharing is becoming increasingly popular. The principle: you look for a car using an app, open it by mobile phone, get in and start driving. Somewhere in the city you put the vehicle on the side of the road and the next one can use it. One of the best known providers is Drive Now.

DriveNow is a car sharing service of the car manufacturer BMW. The project was started on June 9, 2011 in Munich as a joint venture of the BMW Group and the car rental company Sixt SE, on March 9, 2018 DriveNow became a wholly owned subsidiary of the BMW Group.

DriveNow offers its services in Munich, Berlin, Dusseldorf, Cologne, Hamburg, Vienna, London, Copenhagen, Milan, Helsinki, Lisbon and Brussels (DriveNow Jahresbilanz, 2017). In October 2017, DriveNow reached the number of 1,000,000 customers. The total number of DriveNow vehicles is 6,510 (as of November 2018). The operators offer in their fleet various Mini models (Convertible, Clubman, Countryman), and the BMW models X1, 1 Series, BMW 2 Series Convertible, BMW X2 and BMW 2 Series Active Tourer, BMW i3 and i8 - exact evolution can be seen in table 1 .

Table 1. Drivenow evolution through the years in different locations

\begin{tabular}{|l|l|l|l|l|}
\hline City & Country & Vehicles & Type & Begin of \\
\hline Munich & Germany & 750 (including 85 electric) & Diesel / gasoline / electric & June 2011 \\
\hline Berlin & Germany & $\begin{array}{l}1400 \text { (including 140 } \\
\text { electric) }\end{array}$ & Diesel / gasoline / electric & September 2011 \\
\hline Dusseldorf & Germany & 310 (including 20 electric) & Diesel / gasoline / electric & January 2012 \\
\hline $\begin{array}{l}\text { San } \\
\text { Francisco }\end{array}$ & United States & 150 & Electric & $\begin{array}{l}\text { Aug. 2012 to Nov. } \\
\text { 2015 }\end{array}$ \\
\hline Cologne & Germany & 310 (including 25 electric) & Diesel / gasoline / electric & October 2012 \\
\hline Hamburg & Germany & 600 (including 200 electric) & Diesel / gasoline / electric & November 2013 \\
\hline Vienna & Austria & 700 (including 20 electric) & Diesel / gasoline / electric & October 2014 \\
\hline London & $\begin{array}{l}\text { United } \\
\text { Kingdom }\end{array}$ & 720 (including 50 electric) & Diesel / gasoline / electric & December 2014 \\
\hline
\end{tabular}




\begin{tabular}{|l|l|l|l|l|} 
Copenhagen & Denmark & 550 (including 350 electric) & Diesel / gasoline / electric & September 2015 \\
\hline Brussels & Belgium & 310 (including 10 electric) & Diesel / gasoline / electric & July 2016 \\
\hline Milan & Italy & 500 (including 20 electric) & Diesel / gasoline / electric & October 2016 \\
\hline Helsinki & Finland & 150 (including 10 electric) & Diesel / gasoline / electric & May 2017 \\
\hline Lisbon & Portugal & 210 (including 40 electric) & Diesel / gasoline / electric & September 2017 \\
\hline
\end{tabular}

Unlike classic car rental, where you rent a vehicle at a fixed location and typically return it after one or more days, the new carsharing models allow you to use free-parked vehicles within minutes in the city area (DriveNow, 2018). The minute costs from 25 cents including fuel and parking fees (when buying minute packages), otherwise from 33 cents. Typically, the car must be parked in the same city in which it was rented. An exception are Dusseldorf and Cologne: Here, at a surcharge, a return in the other city is possible. For the parking of the vehicle in the neighboring city an additional "service fee" of 8 Euro is charged.

A monthly fee is not applicable for the use. However, you have to register once online and pay a registration fee of 29 euros. It is possible to reserve the vehicle once free of charge for up to 15 minutes without cancellation fees. Alternatively, you can book up to eight hours for 10 cents a minute. Arriving at the car, the same is opened either by app or by means of the glued into the customer card RFID chips. For the latter, the card must be held to the transponder in the lower right area of the windshield. After successful status query, which is indicated by a permanent green of the previously flashing yellow LED, the vehicle opens. To start the engine it is necessary to enter a PIN. Like its competitors, DriveNow pays flat-rate parking fees to the city's municipalities to allow the customer free parking in paid parking zones.

In the DriveNow app all BMW and MINI cars can be reserved. The following options can already be set on the way to the car in the app: navigation-destination entry, booking of hour and experience packages, distinction between private and business trip. Features such as a simplified opening of the vehicle. As soon as the vehicle is approached at $150 \mathrm{~m}$, the user will receive a push message that allows him to open the car with just one click.

If we analyze the key aspects of DriveNow business plan, we see that most of their services are offered via IoT - connecting the customer to the car via the mobile application and internet. DriveNow business plan structure is as follows. Partners (DriveNow, 2018) are owners of big parking operators, green mountain energy association, power stations, green park council and insurance companies. Activity (DriveNow, 2018) is application development and maintenance, checking customer feedback and engaging with partners. Resources are their car fleet, their customers worldwide and venture funds. Value proposition (DriveNow, 2018) is composed of the idea to be mobile every time, parking without hassle, no need for searching a parking slot, being flexible without earning a car, electric driving and zero emissions. The customers (DriveNow, 2018) are all citizens without an own car, there relationship (DriveNow, 2018) with them is simple: always online, selfservice, anywhere, anytime and any device - contacting them through simple channels (DriveNow, 2018) such as mobile applications, website, parking and power stations. The revenue stream (DriveNow, 2018) comes from rental fees, with focus on quality services and the cost structure (DriveNow, 2018) is direct and clear: fleet, marketing, promotion, application development, staff, parking agreements and insurances. 


\section{Conclusion}

Considering the European Union documents (EU-TEN407, 2009), the IoT will definitely improve the quality of citizens' life. Intelligent objects are set to confirm that they will be able "to comprehend their own properties and potentialities", "make autonomous decisions" and "take proactive steps to meet the targets they have been set". It is perfectly conceivable that future intelligent systems will be able to carry out all kinds of activities and tasks and, "at a certain point, react to their environment, i.e. adapt to the world around them, alter their configuration, repair any faults themselves - and even decide who can access them or switch owners".

The full potential of both the Internet of Things and business modeling could only be predicted and therefore the immersion of IoT in business and innovative systems will continue as an open research area in the near future. The bases are already stated in recent publications. For example, in (Basingab et al., 2017) "a predictive maintenance business model that uses IoT as the core of the business" is described. In (Nedeltcheva \& Shoicova, 2017) the authors conclude that more and more IoT solutions providers open their platforms to other developers in order to test and provide feedback for their systems and moreover to support cloud solutions, to break the barriers for innovation and business cooperation.

\section{References}

Ashton, K. (2009). That "Internet of Things" thing, RFID Journal, 22, June 2009. Retrieved from http://www.rfidjournal.com/articles/view?4986

Barnaghi, P., Wang, W., Henson, C., \& Taylor, K. (2012) Semantics for the Internet of Things: early progress and back to the future. International Journal on Semantic Web and Information Systems, 8(1), 1-21.

Basingab, M., Rabelo, L., Nagadi, K., Rose, C., Gutiérrez, E., \& Jung, W II. (2017). Business modeling based on internet of things: a case study of predictive maintenance software using ABS model, In Hamdan, H., Boubiche, D.E., Hidoussi, F. (Eds.). Proceedings of the Second International Conference on Internet of things, Data and Cloud Computing (ICC '17). ACM, New York, NY, USA, Article 11, 5 pages.

Bucherer, E., \& Uckelmann, D. (2011). Business models for the Internet of Things. In D. Uckelmann, M. Harrison \& F. Michahelles (Hrsg.), Architecting the Internet of Things (S. 253-277). Berlin: Springer.

Bieger, T., Knyphausen, A. D., Krys, C. (2011). Business Model Innovation. Springer. 2011 edition, pp. 15 - 18.

CokeMachine (2019). The "Only" Coke Machine on the Internet. Retrieved from https://www.cs.cmu.edu/ coke/history_long.txt

Cvijikj, I. P., \& Michahelles, F. (2011). The toolkit approach for end-user participation in the Internet of Things. In D. Uckelmann, M. Harrison \& F. Michahelles (Hrsg.), Architecting the Internet of Things (S. 65-96). Berlin: Springer.

Eleftherakis, E., Pappas, D., Lagkas, T., Rousis, K., \& Paunovski, O. (2015). Architecting the IoT Paradigm: A Middleware for Autonomous Distributed Sensor Networks. International Journal of Distributed Sensor Networks, vol. 2015, Article ID 139735, 17 pages.

DriveNow (2018). 30 Jahre Carsharing in Deutschland - wir gestalten die Mobilität der Zukunft. https://www.drive-now.com/de/de/blog/news/30-jahre-carsharing 
DriveNow (2018). Eine Million Gründe, euch DANKE zu sagen. https://www.drivenow.com/de/de/blog/news/one-in-a-million

DriveNow (2018). Jetzt noch besser - Holt euch das App-Update. https://www.drivenow.com/de/de/blog/news/appupdate_de

DriveNow (2018). Alexa, öffne DriveNow und reserviere mir das nächste Auto. https://www.drive-now.com/de/de/blog/news/alexa

DriveNow (2018). Mit DriveNow 250 Mal elektrisch um die Welt. https://www.drive-

PICBE | 1202 now.com/de/de/blog/news/elektrisch-um-die-welt

DriveNow (2018). Die BMW \& MINI Credit Cards sind da. https://www.drivenow.com/de/de/blog/news/die-bmw-und-mini-credit-cards-sind-da

DriveNow Jahresbilanz (2017). DriveNow Jahresbilanz 2017. https://content.drivenow.com/sites/default/files/2018-01/2018.01.10_DriveNow_Jahresbilanz_2017.pdf

Drucker, P. F. (1994). The Theory of the Business. Harvard Business Review. https://hbr.org/1994/09/the-theory-of-the-business

EU-TEN407 (2009). Internet of Things - An action plan for Europe. European Union, European Economic and Social Committee Communication, TEN/407-EESC-20091951, Brussels. Retrieved from https://www.eesc.europa.eu/en/our-work/opinionsinformation-reports/opinions/internet-things-action-plan-europe

Fraunhofer-Institut für Integrierte Schaltungen IIS (2019). Internet of Things - Geschäftsfeld im Bereich Kommunikationssysteme. https://www.iis.fraunhofer.de/de/ff/kom/iot.html

Gassmann, O., Frankenberger, K., \& Csik, M. (2018). The Business Model Navigator: 55 Models That Will Revolutionise Your Business. Munich: Carl Hanser Verlag.

Gross, N. (1999). The earth will don an electronic skin, into 21 ideas for the $21^{\text {st }}$ century. Businessweek online Magazine, issue August 30, 1999. Retrieved from http://www.businessweek.com/1999/99\_35/b3644024.htm

Gubbi, J., Buyya, R., Marusic, S., \& Palaniswami, M. (2013). Internet of Things (IoT): A vision, architectural elements, and future directions. Future Generation Computer Systems, 29(7), 1645-1660.

Koreshoff, T.L., Robertson, T., \& Leong, T.W. (2013). Internet of things: a review of literature and products. In Shen, H., Smith, R., Paay, J., Calder, P., Wyeld, T. (Eds) Proceedings of the 25th Australian Computer-Human Interaction Conference: Augmentation, Application, Innovation, Collaboration (OzCHI '13) (pp 335-344). ACM, New York, NY, USA

Miorandi, D., Sicari, S., De Pellegrini, F., \& Chlamtac, I. (2012). Internet of Things: Vision, applications and research challenges. Ad Hoc Networks, 10(7), 1497-1516.

Moon, H., \& Pan, S.B. (2014). Long Distance Face Recognition for Enhanced Performance of Internet of Things Service Interface, Computer Science and Information Systems, 11(3), 961-974.

Nedeltcheva, G.N., \& Shoikova, E. (2017). Models for Innovative IoT Ecosystems. In Wen, T. (Eds). Proceedings of the International Conference on Big Data and Internet of Thing (BDIOT2017) (pp 164-168), ACM, New York, NY, USA.

Office of the National Director of Intelligence. (2008). Disruptive Technologies Global Trends 2025. Appendix F: The Internet of Things (Background), SRI Consulting Business 
Intelligence.

Retrieved

from

http://web2.vsevteme.ru/attachments/show? content=6799

Osterwalder, A., Pigneur, Y., Bernarda, G., \& Smith, A. (2014). Value Proposition Design. Wiley, New Jersey.

Osterwalder, A., \& Pigneur, Y. (2011). Business Model Generation - A Handbook for Visionaries, Game Changers, and Chall. Lausanne, Switzerland.

Porter, M.E. (2014) Harvard business review: how smart, connected products are 1203 transforming competition. https://hbr.org/2014/11/how-smart-connectedproducts-are-transforming-competition.

SAP. (2015). Thought leadership paper Internet of Things, SAP brings you the Internet of Things for business. http://www.sap.com/bin/sapcom/en_us/downloadasset.201411-nov-12-17.sap-brings-you-the-internet-of-things-for-business-pdf.html.

TechoPedia. Internet of Things definition. (2019). TechoPedia portal. Retrieved from https://www.techopedia.com/definition/28247/internet-of-things-iot

Tesla, N. (1904). The transmission of electrical energy without wires. Electrical World and Engineer Magazine. 5 March 1904. Retrieved from http://www.tfcbooks.com/tesla/1904-03-05.htm

Teece, D. (2010). Business models, business strategy and innovation. Long Range Planning, 43, pp. 172-194.

Tellis, W. M. (1997). Application of a Case Study Methodology . The Qualitative Report, 3(3), 1-19. Retrieved from https://nsuworks.nova.edu/tqr/vol3/iss3/1.

Tohanean, D., Toma, S. G. (2018). Innovation, a key element of business models in the fourth industrial revolution, Network Intelligence Studies, Volume VI, Issue 12, 121-130.

Wikipedia (2019).

Geschäftsmodell. https://de.wikipedia.org/wiki/Gesch\%C3\%A4ftsmodell

Yin, R. K. (1994). CASE STUDY RESEARCH - Design and Methods, Sage Publications, Second Edition, 12, 17-20. 